Journal of mathematics and computer Science $\quad 8$ (2014) 1 - 20

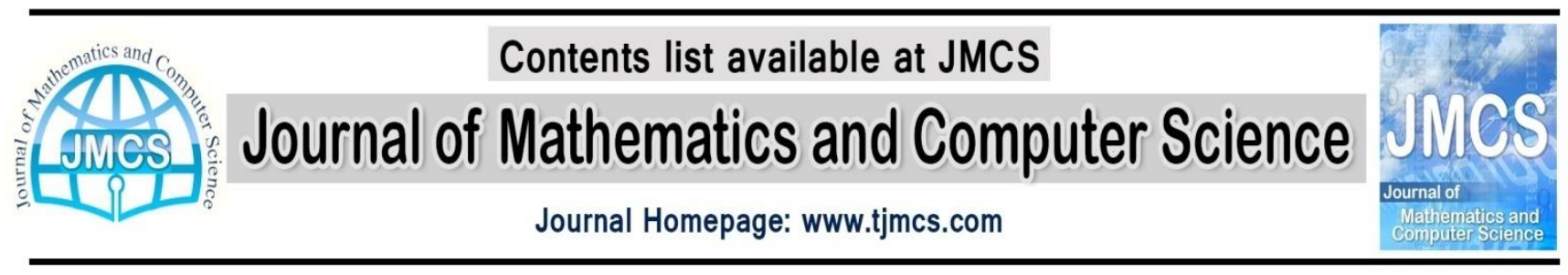

\title{
Fuzzy ANP Approach for New Application: Greenhouse Location Selection; a Case in Iran
}

\author{
Nahid Rezaeiniya ${ }^{1}$, Abdolhamid Safaei Ghadikolaei ${ }^{2}$, \\ Javad Mehri-Tekmeh ${ }^{3}$, Hamidreza Rezaeiniya ${ }^{4}$ \\ ${ }^{1}$ Firoozkooh Branch, Islamic Azad University, Firoozkooh, Iran, Department of industrial Engineering, \\ ${ }^{2}$ Mazandaran University, Faculty of industry management, \\ ${ }^{3}$ University of Tabriz, Tabriz, Iran, Department of mathematics, \\ ${ }^{4}$ Firoozkooh Branch, Islamic Azad University, Firoozkooh, Iran, Department of industrial Management \\ Inah.rezaeiniya@gmail.com, ${ }^{2} A b . s a f a e i @ u m z . a c . i r$,

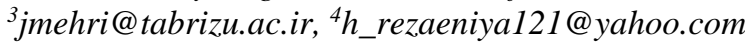

Article history:

Received February 2013

Accepted May 2013

Available online June 2013

\begin{abstract}
Selection of the most appropriate location for investor is an important problem which requires assessment and analysis of several factors. The greenhouse locating has become one of the most important problems for investors; it is a complicated problem and a decision under a variety of factors. The selection of a location among alternative locations is a multi-criteria decision-making problem including both quantitative and qualitative criteria. In this paper, we describe the research and development of hybrid FMCDM methods for greenhouse locating in Iran. Analytic network process gave us a flexibly structure for greenhouse locating, this structure found the relative weights of criteria and ranked the alternatives too.
\end{abstract}

Keywords: Analytic network process (ANP), Fuzzy logic, Locating, Greenhouse.

\section{Introduction}

It is the first duty of investors to transform financial resources in to investments in the right places at the right times and earn benefits. However, where to invest and how to invest is always a risky and complicated problem [1]. The construction of greenhouse is one of investors that nowadays lack of proper management in site selection and construction of greenhouse, cause lack of productivity in this sector of agriculture. Due to population growth and increasing per capita consumption, supply of food needs is an important problem for people and countries. In this regard, greenhouse production has been leading to increase productivity of limited resources of water and soil [2]. Greenhouse is a place that covered with transparent material and its temperature, light, humidity and other environmental factors can be managed [3]. The first point for the construction of greenhouses is to choose the appropriate location [2]. For greenhouses locating must consider several factors: heating supply, greenhouse expansion plans, access to electricity, access to specialized labor, access to fuel [2], land costs, costs of 
construction, raw materials [3], regional economic situation, laws relating to land within the urban [4], use of appropriate soil, labor costs, access to proper transportation [2,3], land topography, proximity to market [2,4], access to adequate water [2,3,4], related industry status, Government [1], and etc. Greenhouse location should be selected according to these factors.

During the stage of making a decision, a lot of criteria should be considered and a decision should be made based on these criteria. As criteria and alternatives increase, it becomes very hard and almost impossible for a human brain to analyze the relation between all the criteria and alternatives and make a decision [1]. Locating is a decision under a variety of factors and can be evaluated according to different aspects, Therefore greenhouse locating can be viewed as a multiple criteria decision making (MCDM) problem. The MCDM methods deal with the process of making decisions in the presence of multiple criteria or objectives [5]. Priority based, outranking, distance-based and mixed methods could be considered as the primary classes of the MCDM methods. In this research Fuzzy Analytic Network Process (FANP) is used for greenhouse locating. ANP method makes the network structure of criteria and alternatives then calculating the weight of each criterion and selecting the best location. In literature, there exist studies that used MCDM for locating problems: Guneri et al. [1] used Fuzzy ANP approach for shipyard locating in Turkey, in that research they propose a network structure with ANP method and solved problem with Chang's method in fuzzy environment. Weber and Chapman [6] used AHP for location intelligence. Kaya [7] used fuzzy AHP for location selection of wastewater treatment plant. Önüt and Soner [8] used AHP and TOPSIS approaches under fuzzy environment for transshipment site selection. Vahidnia et al. [9] used fuzzy AHP for Hospital site selection in Iran. Kuo [10] used ANP, Fuzzy DEMATEL and TOPSIS in international distribution center locating problem. Chou et al. [11] used fuzzy multi-criteria decision model for international tourist hotels location selection. Önüt et al. [12] studied shopping center site selection; they used Fuzzy TOPSIS and Fuzzy AHP in the research. Ozcan et al. [13] used ELECTRE for multi criteria analysis of multi-criteria decision making methodologies and implementation of a warehouse location selection problem. Banias et al. [14] used ELECTRE for optimal location of a construction and demolition waste management facility. Brauers and Zavadskas [15] used multi objective optimization by ratio analysis (MOORA) in location theory with a simulation for a department store. Turskis and Zavadskas [16] used a new fuzzy additive ratio assessment method (ARAS-F) for analysis in order to select the logistics centers locations and Radfar et al. [17] used AHP-COPRAS-G for forest road locating. In this paper, we classify greenhouse locating's criteria in eight classes and use a hybrid model of MCDM methods as a guideline for investors. Fuzzy ANP is used to select the best location for greenhouses. To illustrate this research, Mazandaran province in Iran selected as a case study.

\section{Methodology}

A firm will be able to take make successful decisions based on its ability to analyze the current situation and forecast for future situations. Enterprises want to utilize their resources efficiently and this is only possible if experience is supported with scientific works [1]. Over the past decades the complexity of economical decisions has increased rapidly, thus highlighting the importance of developing and implementing sophisticated and efficient quantitative analysis techniques for supporting and aiding economical decision-making [18]. Multiple criteria decision making (MCDM) is an advanced field of operations research, provides decision makers and analysts a wide range of methodologies, which are overviewed and well suited to the complexity of economical decision problems [19, 20, 21]. Multiple criteria analysis (MCA) provides a framework for breaking a problem into its constituent parts. MCA provides a means to investigate a number of alternatives in light of conflicting priorities [22, 23, 24].

\subsection{Analytic Network Process}


The ANP, also introduced by Saaty, is a generalization of the AHP [25]. Saaty [25] suggested the use of AHP to solve the problem of independence on alternatives or criteria, and the use of ANP to solve the problem of dependence among alternatives or criteria. Many decision-making problems cannot be structured hierarchically because they involve the interaction and dependence of higher level elements on lower level elements [26]. This is a network system. However in ANP, criteria in the lower level may provide feedback to the criteria in the higher level, and the Inter dependence among the criteria in the same level is permitted [27]. Another difference between AHP and ANP in calculation process is that a new concept "super matrix" is introduced in ANP [27].

The recent applications of ANP method in shortly are listed below:

- Boran et al. [28] used ANP for personnel selection.

- Dagdeviren et al. [29] applied fuzzy ANP model to identify faulty behavior risk (FBR) in work system.

- Ayag and Ozdemir [30] applied fuzzy ANP approach to concept selection.

$\circ \quad$ Yazgan [31] applied fuzzy ANP for selection of dispatching rules.

- Kuo [32] used ANP, Fuzzy DEMATEL and TOPSIS in international distribution center locating problem.

The application steps of ANP are as follows [33, 34]:

Forming the Network Structure:

Firstly, criteria, sub criteria and alternatives are defined. Then, the clusters of elements are determined. Network is formed based on relationship among clusters and within elements in each cluster. There are few different relationships that have effects. Direct effect may be considered as a regular dependency in a standard hierarchy. Indirect effect dependency of which is not direct and must flow through another criteria or alternative. Another effect is the self-interaction one. Last are interdependencies among criteria which form a mutual effect.

Forming Pairwise Comparison Matrices and Obtaining Priority Vector:

Pair wise comparisons are performed on the elements within the clusters as they influence each cluster and on those that it influences, with respect to that criterion. The pairwise comparisons are made with respect to a criterion or sub-criterion of the control hierarchy [33]. Thus, importance weights of factors are determined. In pairwise comparison, decision makers compare two elements. Then, they determine the contribution of factors to the result [34].

The values of pairwise comparisons are allocated in comparison matrix and local priority vector is obtained from eigenvector which is calculated from this equation:

$$
A W=\lambda_{e n b} w
$$

In this equation, $A, W$ and $\lambda_{e n b}$ stands for the pairwise comparison matrix, eigenvector and eigenvalue, respectively.

Saaty has proposed normalization algorithm for approximate solution for $w$ [35].

The matrix which shows the comparison between factors is obtained as follows:

$$
A=\left\lfloor a_{i j}\right\rfloor_{n \times n}, i=\overline{1, n} ; j=\overline{1, n}
$$

Significance distribution of factors as percentage is obtained as follows: 


$$
\begin{aligned}
B_{i} & =\left\lfloor b_{i j}\right\rfloor_{n \times 1}, i=\overline{1, n} \\
b_{i j} & =a_{i j} / \sum_{i=1}^{n} a_{i j} \\
C & =\left\lfloor b_{i j}\right\rfloor_{n \times n}, i=\overline{1, n} ; j=\overline{1, n} \\
w_{i} & =\sum_{j=1}^{n} c_{i j} / n \\
W & =\left[w_{i}\right]_{\imath \times 1}
\end{aligned}
$$

\section{Forming Super matrix and Limit Super Matrix:}

The overall structure of super matrix is similar to Markov chain process. [25, 36]. To obtain global priority in a system that has interdependent effects, all local priority vectors are allocated to the relevant columns of super matrix. Consequently, super matrix is a limited matrix and every part of it shows the relationship between two elements in the system. The long term relative impacts of the elements to each other are obtained by raising the super matrix power. To equalize the importance weights, power of the matrix is raised to the $2 k+1$, where $k$ is an arbitrary large number. The new matrix is called limited Super matrix [25]. The consistency of elements comparisons are calculated as follows:

$$
\begin{gathered}
D=\left\lfloor a_{i j}\right\rfloor_{h \times n} \times\left[w_{i}\right]_{n \times 1}=\left[d_{i}\right]_{h \times 1} \\
E_{i}=d_{i} / w_{i} ; i=\overline{1, n} \\
\lambda=\sum_{i=1}^{n} E_{i} / n \\
C I=(\lambda-n) /(n-1) \\
C R=C I / R I
\end{gathered}
$$

In the equations above, $C I, R I$ and $C R$ represent consistency indicator, random indicator and consistency ratio, respectively. Consistency of pairwise matrix is checked by consistency index $(C I)$. For accepted consistency, $C I$ must be smaller than 0.10 [35]. 
2.2. Fuzzy method: Zadeh [37] first introduced the fuzzy set theory to deal with the uncertainty due to imprecision or vagueness. Let the universe of discourse $X$ be the subset of real numbers $\mathrm{R}$. A fuzzy set $\tilde{A}=\left\{\left(x, \mu_{\tilde{A}}(x) \mid x \in X\right)\right\}$ is a set of ordered pairs, where $\mu_{\tilde{A}}(x)$ is called the membership function which assigns to each object $x$ a grade of membership ranging between zero and one. In this research, triangular fuzzy numbers are used to represent subjective pair-wise comparisons of experts' judgments; the triangular fuzzy conversion scale used to convert linguistic values into fuzzy scales in the evaluation model of this paper is shown in Table 1.

Table 1. Triangular fuzzy conversion [38]

\begin{tabular}{|c|c|}
\hline Linguistic scale for importance & Triangular fuzzy scale $(a, b, c)$ \\
\hline \multicolumn{2}{|c|}{ Just equal $\quad(1,1,1)$} \\
\hline Equal importance & $(1,1,3)$ \\
\hline \multicolumn{2}{|c|}{ Weak importance of one over another $\quad(1,3,5)$} \\
\hline \multicolumn{2}{|c|}{ Essential or strong importance $\quad(3,5,7)$} \\
\hline \multicolumn{2}{|l|}{ Very strong importance } \\
\hline \multicolumn{2}{|c|}{$\begin{array}{ll}\text { Extremely preferred } & (7,9,9)\end{array}$} \\
\hline \multicolumn{2}{|c|}{$\begin{array}{l}\text { If factor } i \text { has one of the above numbers assigned to it when compared } \\
\text { to factor } j \text {, then } j \text { has the reciprocal value when compared whit } \\
\text { reciprocals of above } M_{1}^{-1} \approx\left(\frac{1}{c_{1}}, \frac{1}{b_{1}}, \frac{1}{a_{1}}\right) \text {. }\end{array}$} \\
\hline
\end{tabular}

This paper applies Chang's extent analysis method [39]. According to Chang's extent analysis method: Step 1: the value of fuzzy synthetic extent is defined, using the standard fuzzy arithmetic, as below:

$$
S_{i}=\sum_{j=1}^{m} M_{i}^{j} \otimes\left[\sum_{i=1}^{n} \sum_{j=1}^{m} M_{i}^{j}\right]^{-1}
$$

Where $M_{i}^{j}$ is a triangular fuzzy number representing the extent analysis value for decision element $i$ with respect to goal $j . M_{i}^{j}$ is the generic element of a fuzzy pair-wise comparison matrix like the one used in the AHP method. To obtain $\sum_{j=1}^{m} M_{i}^{j}$ perform the fuzzy addition operation of m extent analysis values for a particular matrix such that: 


$$
\sum_{j=1}^{m} \boldsymbol{M}_{i}^{j}=\left(\sum_{i=1}^{m} a_{j}, \sum_{j=1}^{m} b_{j}, \sum_{j=1}^{m} c_{j}\right)
$$

And to obtain $\left[\sum_{i=1}^{n} \sum_{j=1}^{m} M_{i}^{j}\right]^{-1}$ perform the fuzzy addition operation of, $M_{i}^{j}(j=1,2, \ldots, m)$ values such that:

$$
\sum_{i=1}^{n} \sum_{j=1}^{m} M_{i}^{j}=\left(\sum_{i=1}^{n} a_{i}, \sum_{i=1}^{n} b_{i}, \sum_{i=1}^{n} c_{i}\right)
$$

And then compute the inverse of the vector such that:

$$
\left[\sum_{i=1}^{n} \sum_{j=1}^{m} M_{i}^{j}\right]^{-1}=\left(\frac{1}{\sum_{i=1}^{n} c_{i}}, \frac{1}{\sum_{i=1}^{n} b_{i}}, \frac{1}{\sum_{i=1}^{n} a_{i}}\right)
$$

Step 2: The degree of possibility of $M_{1} \geq M_{2}$ is defined as:

$$
V\left(M_{1} \geq M_{2}\right)=\operatorname{Sup}_{x \geq y}\left[\min \left(\mu_{M_{1}}(x), \mu_{M_{2}}(y)\right)\right]
$$

And can be equivalently expressed as follows:

$$
V\left(M_{1} \geq M_{2}\right)=h g t\left(M_{2} \cap M_{1}\right)=\mu_{M_{2}}(d)=\left\{\begin{array}{cl}
1, & \text { if } b_{1} \geq b_{2} \\
0, & \text { if } a_{2} \geq c_{1} \\
\frac{c_{1}-a_{2}}{\left(c_{1}-a_{2}\right)-\left(b_{2}-b_{1}\right)} & \text { otherwise }
\end{array}\right.
$$

Where $d$ is the ordinate of the highest intersection point D between $\mu_{M_{1}}$ and $\mu_{M_{2}}$. To compare $M_{1}$ and $M_{2}$, we need both the values of $V\left(M_{1} \geq M_{2}\right)$ and $V\left(M_{2} \geq M_{1}\right)$. This is given in figure 1 .

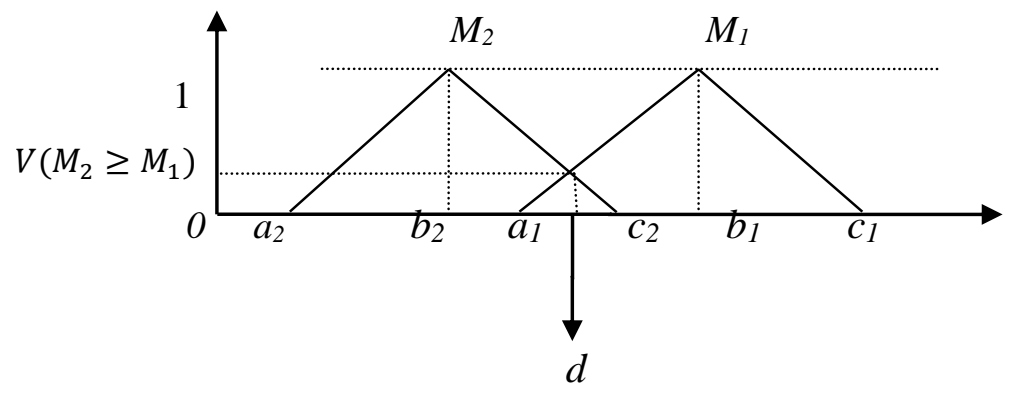

Figure 1. Intersection between $M_{1}$ and $M_{2}$. 
Step 3: The degree of possibility for a convex fuzzy number to be greater than $\mathrm{k}$ convex fuzzy number $M_{i}(i=1,2, \ldots, k)$ can be defined by

$$
\begin{aligned}
& V\left(M \geq M_{1}, M_{2}, \ldots, M_{k}\right)=V\left[\left(M \geq M_{1}\right) \text { and }\left(M \geq M_{2}\right) \text { and } \ldots \text { and }\left(M \geq M_{k}\right)\right]= \\
& \min V\left(M \geq M_{i}\right), i=1,2,3, \ldots, k .
\end{aligned}
$$

Assume that:

$$
d^{\prime}\left(A_{i}\right)=\min V\left(S_{i} \geq S_{k}\right)
$$

For $k=1,2, \ldots, n ; k \neq i$. then the weight vector is given by

$$
W^{\prime}=\left(d^{\prime}\left(A_{1}\right), d^{\prime}\left(A_{2}\right), \ldots, d^{\prime}\left(A_{n}\right)\right)^{T}
$$

Where $A_{i}(i=1,2, \ldots, n)$ are $\mathrm{n}$ decisions elements, step 4: via normalization, the normalized weight vectors are

$$
W=\left(d\left(A_{1}\right), d\left(A_{2}\right), \ldots, d\left(A_{n}\right)\right)^{T}
$$

Where $W$ is a non-fuzzy number.

\section{Greenhouse locating based on Fuzzy ANP method}

\subsection{Identification of necessary criteria for greenhouse locating}

The aim of this study is to utilize a hybrid model of MCDM methods for greenhouse locating. Mazandaran province is locating in north of the Iran and is one of the best places for greenhouse. There

\begin{tabular}{|c|c|}
\hline Clusters name & Sub-criteria \\
\hline Government $\left(\mathrm{C}_{1}\right)$ & Government policy $C_{1-1}$ \\
\hline Labor $\left(\mathrm{C}_{2}\right)$ & $\begin{array}{l}\text { Access to labor } \mathrm{C}_{2-1} \\
\text { Labor cost } \mathrm{C}_{2-2}\end{array}$ \\
\hline Physical condition $\left(\mathrm{C}_{3}\right)$ & $\begin{array}{l}\text { Land cost } \mathrm{C}_{3-1} \\
\text { Cost for Construction } \mathrm{C}_{3-2} \\
\text { Enlargement of greenhouse } \\
\mathrm{C}_{3-3}\end{array}$ \\
\hline $\begin{array}{l}\text { Environment condition } \\
\left(\mathrm{C}_{4}\right)\end{array}$ & $\begin{array}{l}\text { Soil } \mathrm{C}_{4-1} \\
\text { Water } \mathrm{C}_{4-2} \\
\text { Topography } \mathrm{C}_{4-3}\end{array}$ \\
\hline Raw material $\left(\mathrm{C}_{5}\right)$ & $\begin{array}{l}\text { Raw material cost } C_{5-1} \\
\text { Raw material access } C_{5-2}\end{array}$ \\
\hline
\end{tabular}
are a lot of greenhouses in this province that they have greenhouse production and expert them too. In this paper we want to select the best city for greenhouses in Mazandaran. For identification of greenhouse's criteria we use of literature review, then a group of experts classify the criteria in eight clusters. The clusters and their criteria are shown in table 2. 


\begin{tabular}{|l|l|}
\hline Special condition $\left(\mathrm{C}_{6}\right)$ & Road access $\mathrm{C}_{6-1}$ \\
& Electricity access $\mathrm{C}_{6-2}$ \\
& Fuel access $\mathrm{C}_{5-3}$ \\
& Near to the market $\mathrm{C}_{6-4}$ \\
\hline Type of greenhouse & Vegetable's greenhouse $\mathrm{C}_{7-1}$ \\
& Plant and Flower's \\
& greenhouse $\mathrm{C}_{7-2}$ \\
& Mushroom's greenhouse $\mathrm{C}_{7-3}$ \\
\hline Alternatives $(\mathrm{A})$ & Amol $\left(\mathrm{A}_{1}\right)$ \\
& Sari $\left(\mathrm{A}_{2}\right)$ \\
& Mahmoodabad $\left(\mathrm{A}_{3}\right)$ \\
& Ramsar $\left(\mathrm{A}_{4}\right)$ \\
& Chaloos $\left(\mathrm{A}_{5}\right)$ \\
\hline
\end{tabular}

The Information about experts is as below:

Table 3. Background Information of Experts

\begin{tabular}{|ccc|ccc|}
\hline Variable & Items & NO & Variable & Items & NO \\
\hline 1)Education & Bachelor & 3 & 3)Sex & Male & 4 \\
background & Master & 3 & & Female & 3 \\
& Ph.D. & 1 & & & \\
\hline 2)Service & $6-10$ & 2 & $4)$ Age & $30-40$ & 5 \\
Tenure & $11-20$ & 4 & & $41-50$ & 2 \\
& $21-30$ & 1 & & & \\
\hline
\end{tabular}

3.2. Forming Pairwise Matrix: A relationship exists among clusters and the elements within the clusters. For example, there is interrelationship between physical condition cluster and type of greenhouse one. Similarly, the sub-criteria $\mathrm{C}_{3-3}$ and $\mathrm{C}_{3-2}, \mathrm{C}_{3-3}$ and $\mathrm{C}_{3-1}$ have an interrelationship but $\mathrm{C}_{3-2}$ and $\mathrm{C}_{3-1}$ doesn't have an impact. According table 2 and relationship that exists among clusters and the elements within the clusters, the analytic network framework for greenhouse locating and the relation between cluster and interrelation between sub-criteria is made and shown in figure 2 .

The pairwise comparisons based on the relationships mentioned above were made among elements by using triangular fuzzy scales that are shown in table 1. For pairwise comparisons we use the experts $\square$ idea. For greenhouse locating based on the figure 2, we need 87 matrixes for pairwise comparisons, 7 matrixes are for relation and 80 matrixes are for interrelationships that are exits between clusters and elements in the clusters. As an example of these matrixes is the labor pairwise comparison matrix (table 4), one of the 7 matrixes that show the other clusters weight on ones. 


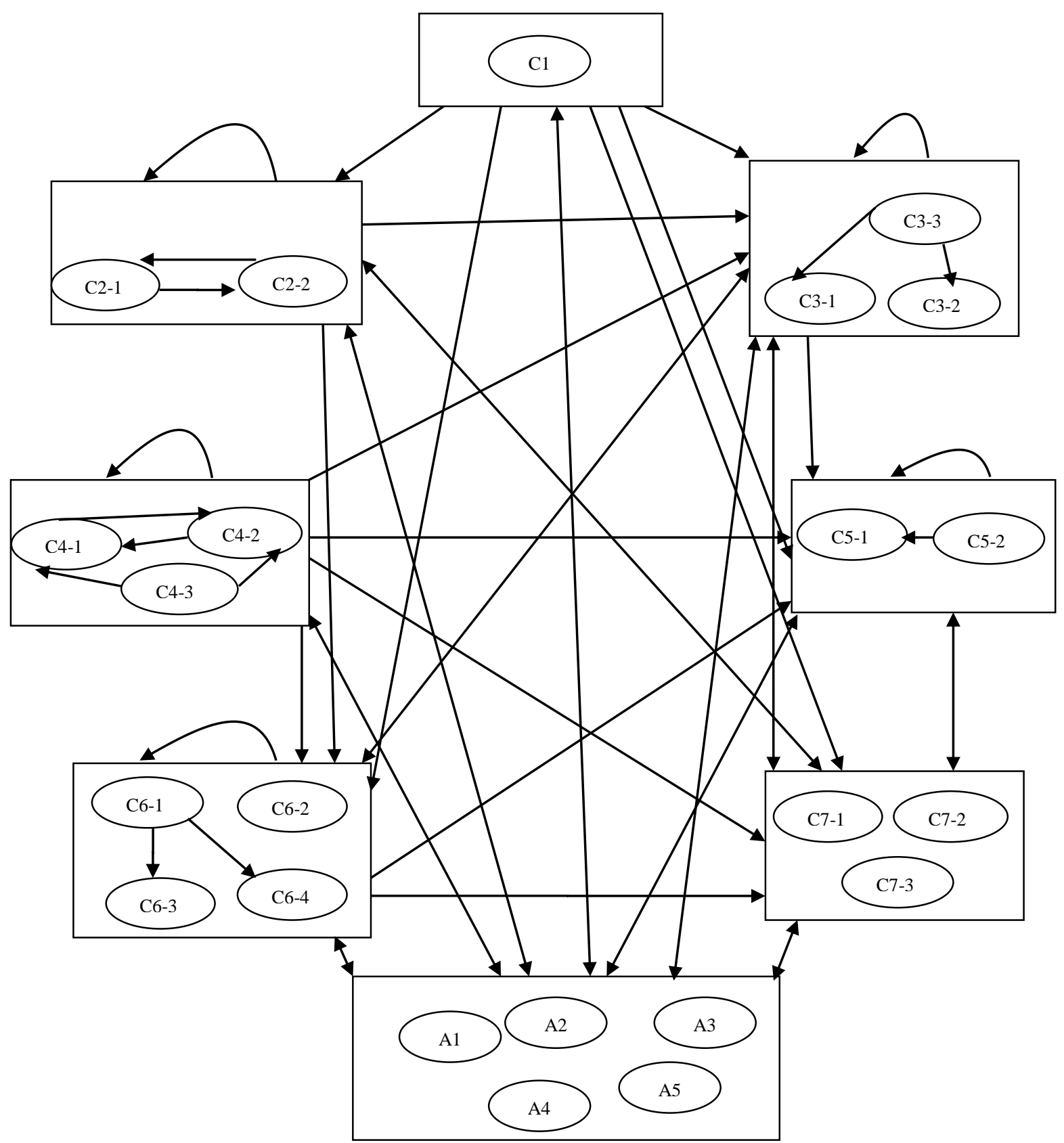

Figure 2. The network framework for greenhouse locating 
Table 4. The labor pairwise comparison matrix under clusters relations

\begin{tabular}{|l|l|l|l|l|l|l|l|l|l|l|l|l|l|l|l|c|}
\hline $\mathrm{C}_{2}$ & \multicolumn{3}{|c|}{$\mathrm{C}_{2}$} & \multicolumn{3}{c|}{$\mathrm{C}_{7}$} & \multicolumn{3}{c|}{$\mathrm{C}_{6}$} & \multicolumn{3}{c|}{$\mathrm{C}_{1}$} & \multicolumn{3}{c|}{$\mathrm{A}$} & $\mathrm{W}$ \\
\hline $\mathrm{C}_{2}$ & 1.000 & 1.000 & 1.000 & 3.557 & 5.593 & 7.612 & 2.054 & 3.093 & 4.209 & 1.135 & 1.710 & 2.430 & 0.868 & 1.570 & 2.083 & 0.404 \\
\hline $\mathrm{C}_{7}$ & 0.131 & 0.179 & 0.281 & 1.000 & 1.000 & 1.000 & 0.732 & 1.186 & 2.203 & 0.228 & 0.306 & 0.447 & 0.293 & 0.637 & 1.089 & 0.052 \\
\hline $\mathrm{C}_{6}$ & 0.238 & 0.323 & 0.487 & 0.454 & 0.843 & 1.365 & 1.000 & 1.000 & 1.000 & 0.273 & 0.394 & 0.693 & 0.367 & 0.637 & 1.254 & 0.041 \\
\hline $\mathrm{C}_{1}$ & 0.412 & 0.585 & 0.881 & 2.236 & 3.271 & 4.389 & 1.442 & 2.539 & 3.659 & 1.000 & 1.000 & 1.000 & 0.754 & 1.152 & 1.913 & 0.291 \\
\hline $\mathrm{A}$ & 0.480 & 0.637 & 1.152 & 0.918 & 1.570 & 3.411 & 0.797 & 1.570 & 2.724 & 0.523 & 0.868 & 1.326 & 1.000 & 1.000 & 1.000 & 0.213 \\
\hline
\end{tabular}

The study topic is fuzzy analytic network process. It means that the current problem would be solved by using fuzzy logic. Fuzzy logic is used in order to eliminate ambiguity and subjectivity using Microsoft Excel. In this research we used Chang's method that the steps of ones are showed, therefore we use equations (13) to (22) to find matrices. These steps for table 4 are shown as below:

Step1. For calculate $S_{i}$, according to equation (15) and (16):

$\left[\sum_{i=1}^{5} \sum_{j=1}^{5} M_{g_{i}}^{j}\right]=(22.893,33.663,48.607)$

$\left[\sum_{i=1}^{5} \sum_{j=1}^{5} M_{g_{i}}^{j}\right]^{-1}=(0.0205,0.029,0.043)$,

and according to equation (13) and (14):

$S_{C_{2}}=(8.614,12.966,17.332) \otimes(0.020,0.297,0.0436)=(0.177,0.385,0.757)$

And so:

$S_{C_{7}}=(0.049,0.098,0.219) \quad S_{C_{6}}=(0.047,0.094,0.209)$

$S_{C_{1}}=(0.120,0.253,0.517) \quad S_{A}=(0.765,0.167,0.419)$

Step2. As an example we put the degree of possibility of $S_{C_{2}}$ as below (see equation (17) and (18)):

$$
\begin{array}{ll}
\mathrm{V}\left(S_{C_{2}} \geq S_{C_{7}}\right)=1 & \mathrm{~V}\left(S_{C_{2}} \geq S_{C_{6}}\right)=1 \\
\mathrm{~V}\left(S_{C_{2}} \geq S_{C_{1}}\right)=1 & \mathrm{~V}\left(S_{C_{2}} \geq S_{A}\right)=1
\end{array}
$$

As equally we calculated another $S_{i}$.

Step3. According to equation (19) and (20) we calculate the greater degree of possibility as below:

$V\left(S_{C_{2}} \geq S_{C_{7}}, S_{C_{6}}, S_{C_{1}}, S_{A}\right)=\operatorname{Min}(1,1,1,1)=1$ 


$$
\begin{aligned}
& V\left(S_{C_{7}} \geq S_{C_{2}}, S_{C_{6}}, S_{C_{1}}, S_{A}\right)=\operatorname{Min}(0.127,1,0.388,0.672,0.127)=0.127 \\
& V\left(S_{C_{6}} \geq S_{C_{2}}, S_{C_{7}}, S_{C_{1}}, S_{A}\right)=\operatorname{Min}(0.100,0.980,0.360,0.646)=0.100 \\
& V\left(S_{C_{1}} \geq S_{C_{2}}, S_{C_{7}}, S_{C_{6}}, S_{A}\right)=\operatorname{Min}(0.721,1,1,1)=0.721 \\
& V\left(S_{A} \geq S_{C_{2}}, S_{C_{7}}, S_{C_{6}}, S_{C_{1}}\right)=\operatorname{Min}(0.527,1,1,0.776)=0.527
\end{aligned}
$$

And we have $W^{\prime}$ according to equation (21):

$$
W^{\prime}=(1,0.127,0.100,0.721,0.527)^{T}
$$

Step 4. According to equation (22) we normalized $W^{\prime}$ :

$$
W=(0.404,0.052,0.041,0.291,0.213)
$$

Where $\mathrm{W}$, is a non-fuzzy number.

As an example of interrelationship cluster matrices we put pairwise comparison matrix of labor clusters' elements on construction cost of physical condition cluster (table 5).

Table 5. The construction cost pairwise comparison matrix under clusters $\square$ interrelationship

\begin{tabular}{|c|c|c|c|c|c|c|c|}
\hline $\mathrm{C}_{3-2}$ & \multicolumn{3}{|c|}{$\mathrm{C}_{2-1}$} & \multicolumn{3}{c|}{$\mathrm{C}_{2-2}$} & $\mathrm{~W}$ \\
\hline $\mathrm{C}_{2-1}$ & 1.000 & 1.000 & 1.000 & 0.423 & 0.656 & 1.218 & 0.387 \\
\hline $\mathrm{C}_{2-2}$ & 0.821 & 1.525 & 2.365 & 1.000 & 1.000 & 1.000 & 0.613 \\
\hline
\end{tabular}

We use equation (13) to (22) for table 6 too. We made all the matrices under relation and interrelation between clusters and elements.

3.3. Forming Super matrix and limit super matrix for Greenhouse locating: After all comparisons and weighting processes are done we obtain super matrix. Initial super matrix (unweighted matrix) is formed by priority vectors which are calculated from pairwise comparison matrices. In initial super matrix, the cells get two values: priority vectors and zero. In the initial super matrix, priority vectors exist in cells where interdependent factors intersect. The zero valued cells consist of no relationship factors. The super matrix of the proposed model is given in Table 6 . 
Table 6. unweighted super matrix for greenhouse locating model

\begin{tabular}{|c|c|c|c|c|c|c|c|c|c|c|c|c|c|c|c|c|c|c|c|c|c|c|c|c|}
\hline & & \multirow{2}{*}{\begin{tabular}{|l|}
$\mathrm{C} 1$ \\
$\mathrm{C} 1-1$ \\
\end{tabular}} & \multicolumn{2}{|c|}{$\mathrm{C} 2$} & \multicolumn{3}{|c|}{ C3 } & \multicolumn{3}{|c|}{$\mathrm{C} 4$} & & \multicolumn{4}{|c|}{ C6 } & \multicolumn{3}{|c|}{ C7 } & \multicolumn{5}{|c|}{ A } \\
\hline & & & C2-1 & C2-2 & C3-1 & C3-2 & C3-3 & C4-1 & C4-2 & C4-3 & C5-1 & C5-2 & C6-1 & C6-2 & C6-3 & C6-4 & C7-1 & C7-2 & C7-3 & A1 & A2 & A3 & A4 & A5 \\
\hline $\mathrm{C} 1$ & C1-1 & 0.000 & 1.000 & 1.000 & 1.000 & 1.000 & 1.000 & 0.000 & 0.000 & 0.000 & 1.000 & 1.000 & 1.000 & 1.000 & 1.000 & 1.000 & 1.000 & 1.000 & 1.000 & 1.000 & 1.000 & 1.000 & 1.000 & 1.000 \\
\hline \multirow[b]{2}{*}{$\mathrm{C} 2$} & C2-1 & 0.000 & 0.000 & 1.000 & 0.000 & 0.387 & 0.590 & 0.000 & 0.000 & 0.000 & 0.000 & 0.000 & 0.000 & 0.000 & 0.000 & 0.000 & 0.656 & 0.787 & 0.932 & 0.500 & 0.543 & 0.673 & 0.643 & 0.706 \\
\hline & C2-2 & 0.000 & 1.000 & 0.000 & 0.000 & 0.613 & 0.410 & 0.000 & 0.000 & 0.000 & 0.000 & 0.000 & 0.000 & 0.000 & 0.000 & 0.000 & 0.344 & 0.213 & 0.068 & 0.500 & 0.457 & 0.327 & 0.357 & 0.294 \\
\hline \multirow{3}{*}{$\mathrm{C} 3$} & C3-1 & 0.000 & 0.000 & 0.000 & 0.000 & 0.000 & 0.000 & 0.000 & 0.000 & 0.000 & 0.000 & 0.000 & 1.000 & 1.000 & 1.000 & 1.000 & 0.787 & 0.689 & 0.754 & 0.754 & 0.626 & 0.754 & 0.871 & 0.960 \\
\hline & C3-2 & 0.000 & 0.000 & 0.000 & 0.000 & 0.000 & 0.000 & 0.000 & 0.000 & 0.000 & 0.000 & 0.000 & 0.000 & 0.000 & 0.000 & 0.000 & 0.213 & 0.311 & 0.246 & 0.246 & 0.375 & 0.246 & 0.129 & 0.040 \\
\hline & C3-3 & 0.000 & 0.000 & 0.000 & 1.000 & 1.000 & 0.000 & 0.000 & 0.000 & 0.000 & 0.000 & 0.000 & 0.000 & 0.000 & 0.000 & 0.000 & 0.000 & 0.000 & 0.000 & 0.000 & 0.000 & 0.000 & 0.000 & 0.000 \\
\hline \multirow[b]{3}{*}{$\mathrm{C} 4$} & C4-1 & 0.000 & 0.000 & 0.000 & 0.482 & 0.000 & 0.065 & 0.000 & 0.905 & 0.000 & 0.081 & 0.000 & 0.000 & 0.000 & 0.000 & 0.000 & 0.398 & 0.433 & 0.449 & 0.379 & 0.372 & 0.372 & 0.410 & 0.431 \\
\hline & C4-2 & 0.000 & 0.000 & 0.000 & 0.395 & 0.000 & 0.719 & 0.683 & 0.000 & 0.000 & 0.485 & 0.000 & 0.000 & 0.000 & 0.000 & 0.000 & 0.516 & 0.431 & 0.532 & 0.382 & 0.367 & 0.367 & 0.371 & 0.373 \\
\hline & C4-3 & 0.000 & 0.000 & 0.000 & 0.123 & 1.000 & 0.217 & 0.317 & 0.095 & 0.000 & 0.434 & 0.000 & 1.000 & 0.000 & 0.000 & 0.000 & 0.086 & 0.136 & 0.019 & 0.239 & 0.261 & 0.261 & 0.219 & 0.195 \\
\hline \multirow[b]{2}{*}{ C5 } & C5-1 & 0.000 & 0.000 & 0.000 & 0.000 & 0.000 & 0.673 & 0.000 & 0.000 & 0.000 & 0.000 & 0.000 & 0.000 & 0.000 & 0.000 & 0.000 & 0.787 & 0.518 & 0.364 & 0.699 & 0.996 & 0.996 & 0.273 & 0.041 \\
\hline & C5-2 & 0.000 & 0.000 & 0.000 & 0.000 & 0.000 & 0.327 & 0.000 & 0.000 & 0.000 & 1.000 & 0.000 & 0.000 & 0.000 & 0.000 & 0.000 & 0.213 & 0.482 & 0.636 & 0.301 & 0.004 & 0.004 & 0.727 & 0.959 \\
\hline \multirow[b]{4}{*}{ C6 } & C6-1 & 0.000 & 1.000 & 1.000 & 0.195 & 0.586 & 0.301 & 0.000 & 0.000 & 0.000 & 1.000 & 1.000 & 0.000 & 0.000 & 1.000 & 1.000 & 0.364 & 0.603 & 0.518 & 0.371 & 0.350 & 0.350 & 0.449 & 0.451 \\
\hline & C6-2 & 0.000 & 0.000 & 0.000 & 0.293 & 0.318 & 0.160 & 0.000 & 0.000 & 0.000 & 0.000 & 0.000 & 0.000 & 0.000 & 0.000 & 0.000 & 0.132 & 0.004 & 0.134 & 0.088 & 0.126 & 0.126 & 0.122 & 0.099 \\
\hline & C6-3 & 0.000 & 0.000 & 0.000 & 0.261 & 0.096 & 0.258 & 0.000 & 0.000 & 0.000 & 0.000 & 0.000 & 0.000 & 0.000 & 0.000 & 0.000 & 0.203 & 0.139 & 0.187 & 0.224 & 0.242 & 0.242 & 0.242 & 0.262 \\
\hline & C6-4 & 0.000 & 0.000 & 0.000 & 0.251 & 0.000 & 0.281 & 0.000 & 0.000 & 0.000 & 0.000 & 0.000 & 0.000 & 0.000 & 0.000 & 0.000 & 0.301 & 0.253 & 0.161 & 0.318 & 0.283 & 0.283 & 0.188 & 0.187 \\
\hline \multirow[b]{3}{*}{ C7 } & C7-1 & 0.000 & 0.404 & 0.797 & 0.000 & 0.803 & 0.374 & 0.000 & 0.000 & 0.000 & 0.802 & 0.530 & 0.000 & 0.000 & 0.000 & 0.000 & 0.000 & 0.000 & 0.000 & 0.028 & 0.359 & 0.359 & 0.006 & 0.018 \\
\hline & C7-2 & 0.000 & 0.495 & 0.049 & 0.000 & 0.133 & 0.345 & 0.000 & 0.000 & 0.000 & 0.114 & 0.183 & 0.000 & 0.000 & 0.000 & 0.000 & 0.000 & 0.000 & 0.000 & 0.965 & 0.476 & 0.476 & 0.685 & 0.572 \\
\hline & C7-3 & 0.000 & 0.101 & 0.153 & 0.000 & 0.064 & 0.282 & 0.000 & 0.000 & 0.000 & 0.084 & 0.287 & 0.000 & 0.000 & 0.000 & 0.000 & 0.000 & 0.000 & 0.000 & 0.007 & 0.165 & 0.165 & 0.310 & 0.410 \\
\hline \multirow[b]{5}{*}{ A } & A1 & 0.219 & 0.306 & 0.176 & 0.339 & 0.319 & 0.333 & 0.259 & 0.459 & 0.205 & 0.230 & 0.278 & 0.368 & 0.351 & 0.313 & 0.373 & 0.229 & 0.210 & 0.292 & 0.000 & 0.000 & 0.000 & 0.000 & 0.000 \\
\hline & A 2 & 0.349 & 0.432 & 0.234 & 0.354 & 0.340 & 0.451 & 0.158 & 0.274 & 0.248 & 0.235 & 0.228 & 0.168 & 0.109 & 0.252 & 0.176 & 0.297 & 0.196 & 0.249 & 0.000 & 0.000 & 0.000 & 0.000 & 0.000 \\
\hline & A3 & 0.033 & 0.039 & 0.265 & 0.219 & 0.243 & 0.032 & 0.138 & 0.001 & 0.207 & 0.172 & 0.157 & 0.251 & 0.227 & 0.205 & 0.159 & 0.178 & 0.149 & 0.112 & 0.000 & 0.000 & 0.000 & 0.000 & 0.000 \\
\hline & A 4 & 0.248 & 0.152 & 0.158 & 0.008 & 0.001 & 0.108 & 0.229 & 0.161 & 0.178 & 0.158 & 0.142 & 0.049 & 0.123 & 0.106 & 0.135 & 0.159 & 0.227 & 0.147 & 0.000 & 0.000 & 0.000 & 0.000 & 0.000 \\
\hline & A5 & 0.152 & 0.071 & 0.167 & 0.079 & 0.097 & 0.075 & 0.216 & 0.105 & 0.163 & 0.205 & 0.194 & 0.164 & 0.190 & 0.124 & 0.156 & 0.137 & 0.218 & 0.200 & 0.000 & 0.000 & 0.000 & 0.000 & 0.000 \\
\hline
\end{tabular}


The weighted matrix is obtained through normalizing of initial matrix, for normalizing the initial matrix we need to Cluster Matrix, The cluster themselves must be compared to establish their relative importance and use it to weight the corresponding blocks of the super matrix to make it column stochastic. The cluster matrix for greenhouse locating is shown in table 7.

Table 7. Cluster matrix for greenhouse locating

\begin{tabular}{|l|l|l|l|l|l|l|l|l|}
\hline \multicolumn{1}{|c|}{$\mathrm{C}_{1}$} & $\mathrm{C}_{2}$ & $\mathrm{C}_{3}$ & $\mathrm{C}_{4}$ & $\mathrm{C}_{5}$ & $\mathrm{C}_{6}$ & $\mathrm{C}_{7}$ & $\mathrm{~A}$ \\
\hline $\mathrm{C}_{1}$ & 0.000 & 0.291 & 0.153 & 0.000 & 0.306 & 0.211 & 0.154 & 0.161 \\
\hline $\mathrm{C}_{2}$ & 0.000 & 0.404 & 0.072 & 0.000 & 0.000 & 0.000 & 0.110 & 0.105 \\
\hline $\mathrm{C}_{3}$ & 0.000 & 0.000 & 0.141 & 0.000 & 0.000 & 0.176 & 0.131 & 0.175 \\
\hline $\mathrm{C}_{4}$ & 0.000 & 0.000 & 0.160 & 0.370 & 0.182 & 0.174 & 0.123 & 0.194 \\
\hline $\mathrm{C}_{5}$ & 0.000 & 0.000 & 0.068 & 0.000 & 0.022 & 0.000 & 0.113 & 0.093 \\
\hline $\mathrm{C}_{6}$ & 0.000 & 0.040 & 0.152 & 0.000 & 0.191 & 0.209 & 0.171 & 0.204 \\
\hline $\mathrm{C}_{7}$ & 0.000 & 0.052 & 0.096 & 0.000 & 0.122 & 0.000 & 0.000 & 0.068 \\
\hline $\mathrm{A}$ & 1.000 & 0.213 & 0.158 & 0.630 & 0.177 & 0.230 & 0.198 & 0.000 \\
\hline
\end{tabular}

Cluster weights of cluster matrix are implicated to unweighted matrix then weighted super matrix is obtained (Table 8).

Weighted super matrix is ready, power of this matrix calculated according Markov $\square \mathrm{s}$ equation (23), when consecutive powers become equal, the power calculating process is over.

$$
\text { limit super matrix }=(\text { weighted super matrix })^{2 k+1}
$$

In our case study, we obtained limit super matrix in eleventh power of weighted super matrix. Limit super matrix for greenhouse locating is shown in table 9. 
Table 8. The Weighted Super matrix for greenhouse locating model

\begin{tabular}{|c|c|c|c|c|c|c|c|c|c|c|c|c|c|c|c|c|c|c|c|c|c|c|c|c|}
\hline & & \multirow{2}{*}{$\begin{array}{l}\text { C1 } \\
\text { C1-1 }\end{array}$} & \multicolumn{2}{|c|}{$\mathrm{C} 2$} & \multicolumn{3}{|c|}{$\mathrm{C} 3$} & \multicolumn{3}{|c|}{$\mathrm{C} 4$} & \multicolumn{2}{|c|}{ C5 } & \multicolumn{4}{|c|}{ C6 } & \multicolumn{3}{|c|}{$\mathrm{C} 7$} & \multicolumn{5}{|c|}{ A } \\
\hline & & & C2-1 & C2-2 & C3-1 & C3-2 & C3-3 & C4-1 & $\mathrm{C} 4-2$ & C4-3 & C5-1 & C5-2 & C6-1 & C6-2 & C6-3 & C6-4 & C7-1 & C7-2 & C7-3 & A1 & A2 & A3 & A4 & A5 \\
\hline $\mathrm{C} 1$ & C1-1 & 0.000 & 0.291 & 0.291 & 0.200 & 0.164 & 0.178 & 0.000 & 0.000 & 0.000 & 0.306 & 0.384 & 0.267 & 0.342 & 0.255 & 0.255 & 0.154 & 0.154 & 0.154 & 0.161 & 0.161 & 0.161 & 0.161 & 0.161 \\
\hline \multirow[b]{2}{*}{$\mathrm{C} 2$} & C2-1 & 0.000 & 0.000 & 0.404 & 0.000 & 0.030 & 0.049 & 0.000 & 0.000 & 0.000 & 0.000 & 0.000 & 0.000 & 0.000 & 0.000 & 0.000 & 0.072 & 0.087 & 0.103 & 0.053 & 0.057 & 0.071 & 0.068 & 0.074 \\
\hline & C2-2 & 0.000 & 0.404 & 0.000 & 0.000 & 0.047 & 0.034 & 0.000 & 0.000 & 0.000 & 0.000 & 0.000 & 0.000 & 0.000 & 0.000 & 0.000 & 0.038 & 0.023 & 0.007 & 0.053 & 0.048 & 0.034 & 0.037 & 0.031 \\
\hline \multirow[b]{3}{*}{ C3 } & C3-1 & 0.000 & 0.000 & 0.000 & 0.000 & 0.000 & 0.000 & 0.000 & 0.000 & 0.000 & 0.000 & 0.000 & 0.223 & 0.285 & 0.213 & 0.213 & 0.103 & 0.090 & 0.099 & 0.132 & 0.109 & 0.132 & 0.152 & 0.168 \\
\hline & C3-2 & 0.000 & 0.000 & 0.000 & 0.000 & 0.000 & 0.000 & 0.000 & 0.000 & 0.000 & 0.000 & 0.000 & 0.000 & 0.000 & 0.000 & 0.000 & 0.028 & 0.041 & 0.032 & 0.043 & 0.066 & 0.043 & 0.023 & 0.007 \\
\hline & C3-3 & 0.000 & 0.000 & 0.000 & 0.185 & 0.152 & 0.000 & 0.000 & 0.000 & 0.000 & 0.000 & 0.000 & 0.000 & 0.000 & 0.000 & 0.000 & 0.000 & 0.000 & 0.000 & 0.000 & 0.000 & 0.000 & 0.000 & 0.000 \\
\hline \multirow[b]{3}{*}{$\mathrm{C} 4$} & C4-1 & 0.000 & 0.000 & 0.000 & 0.101 & 0.000 & 0.012 & 0.000 & 0.335 & 0.000 & 0.015 & 0.000 & 0.000 & 0.000 & 0.000 & 0.000 & 0.049 & 0.053 & 0.055 & 0.074 & 0.072 & 0.072 & 0.080 & 0.084 \\
\hline & C4-2 & 0.000 & 0.000 & 0.000 & 0.083 & 0.000 & 0.134 & 0.253 & 0.000 & 0.000 & 0.088 & 0.000 & 0.000 & 0.000 & 0.000 & 0.000 & 0.064 & 0.053 & 0.065 & 0.074 & 0.071 & 0.071 & 0.072 & 0.072 \\
\hline & C4-3 & 0.000 & 0.000 & 0.000 & 0.026 & 0.172 & 0.040 & 0.117 & 0.035 & 0.000 & 0.079 & 0.000 & 0.220 & 0.000 & 0.000 & 0.000 & 0.011 & 0.017 & 0.002 & 0.046 & 0.051 & 0.051 & 0.042 & 0.038 \\
\hline \multirow[b]{2}{*}{ C5 } & C5-1 & 0.000 & 0.000 & 0.000 & 0.000 & 0.000 & 0.054 & 0.000 & 0.000 & 0.000 & 0.000 & 0.000 & 0.000 & 0.000 & 0.000 & 0.000 & 0.089 & 0.059 & 0.041 & 0.065 & 0.093 & 0.093 & 0.025 & 0.004 \\
\hline & C5-2 & 0.000 & 0.000 & 0.000 & 0.000 & 0.000 & 0.026 & 0.000 & 0.000 & 0.000 & 0.022 & 0.000 & 0.000 & 0.000 & 0.000 & 0.000 & 0.024 & 0.054 & 0.072 & 0.028 & 0.000 & 0.000 & 0.068 & 0.089 \\
\hline \multirow[b]{4}{*}{ C6 } & C6-1 & 0.000 & 0.040 & 0.040 & 0.039 & 0.096 & 0.053 & 0.000 & 0.000 & 0.000 & 0.191 & 0.240 & 0.000 & 0.000 & 0.253 & 0.253 & 0.062 & 0.103 & 0.089 & 0.076 & 0.071 & 0.071 & 0.092 & 0.092 \\
\hline & C6-2 & 0.000 & 0.000 & 0.000 & 0.058 & 0.052 & 0.028 & 0.000 & 0.000 & 0.000 & 0.000 & 0.000 & 0.000 & 0.000 & 0.000 & 0.000 & 0.023 & 0.001 & 0.023 & 0.018 & 0.026 & 0.026 & 0.025 & 0.020 \\
\hline & C6-3 & 0.000 & 0.000 & 0.000 & 0.052 & 0.016 & 0.046 & 0.000 & 0.000 & 0.000 & 0.000 & 0.000 & 0.000 & 0.000 & 0.000 & 0.000 & 0.035 & 0.024 & 0.032 & 0.046 & 0.049 & 0.049 & 0.049 & 0.054 \\
\hline & C6-4 & 0.000 & 0.000 & 0.000 & 0.050 & 0.000 & 0.050 & 0.000 & 0.000 & 0.000 & 0.000 & 0.000 & 0.000 & 0.000 & 0.000 & 0.000 & 0.052 & 0.043 & 0.027 & 0.065 & 0.058 & 0.058 & 0.038 & 0.038 \\
\hline \multirow[b]{3}{*}{$\mathrm{C} 7$} & C7-1 & 0.000 & 0.021 & 0.041 & 0.000 & 0.082 & 0.042 & 0.000 & 0.000 & 0.000 & 0.098 & 0.081 & 0.000 & 0.000 & 0.000 & 0.000 & 0.000 & 0.000 & 0.000 & 0.002 & 0.024 & 0.024 & 0.000 & 0.001 \\
\hline & C7-2 & 0.000 & 0.026 & 0.003 & 0.000 & 0.014 & 0.038 & 0.000 & 0.000 & 0.000 & 0.014 & 0.028 & 0.000 & 0.000 & 0.000 & 0.000 & 0.000 & 0.000 & 0.000 & 0.066 & 0.032 & 0.032 & 0.047 & 0.039 \\
\hline & C7-3 & 0.000 & 0.005 & 0.008 & 0.000 & 0.007 & 0.031 & 0.000 & 0.000 & 0.000 & 0.010 & 0.044 & 0.000 & 0.000 & 0.000 & 0.000 & 0.000 & 0.000 & 0.000 & 0.000 & 0.011 & 0.011 & 0.021 & 0.028 \\
\hline \multirow[b]{5}{*}{ A } & A1 & 0.219 & 0.065 & 0.038 & 0.070 & 0.054 & 0.061 & 0.163 & 0.289 & 0.205 & 0.041 & 0.062 & 0.107 & 0.131 & 0.087 & 0.104 & 0.045 & 0.042 & 0.058 & 0.000 & 0.000 & 0.000 & 0.000 & 0.000 \\
\hline & $\mathrm{A} 2$ & 0.349 & 0.092 & 0.050 & 0.073 & 0.057 & 0.083 & 0.099 & 0.173 & 0.248 & 0.042 & 0.051 & 0.049 & 0.041 & 0.070 & 0.049 & 0.059 & 0.039 & 0.049 & 0.000 & 0.000 & 0.000 & 0.000 & 0.000 \\
\hline & A3 & 0.033 & 0.008 & 0.056 & 0.045 & 0.041 & 0.006 & 0.087 & 0.001 & 0.207 & 0.030 & 0.035 & 0.073 & 0.084 & 0.057 & 0.044 & 0.035 & 0.029 & 0.022 & 0.000 & 0.000 & 0.000 & 0.000 & 0.000 \\
\hline & A4 & 0.248 & 0.032 & 0.034 & 0.002 & 0.000 & 0.020 & 0.144 & 0.102 & 0.178 & 0.028 & 0.031 & 0.014 & 0.046 & 0.029 & 0.038 & 0.032 & 0.045 & 0.029 & 0.000 & 0.000 & 0.000 & 0.000 & 0.000 \\
\hline & A5 & 0.152 & 0.015 & 0.036 & 0.016 & 0.016 & 0.014 & 0.136 & 0.066 & 0.163 & 0.036 & 0.043 & 0.048 & 0.071 & 0.035 & 0.043 & 0.027 & 0.043 & 0.040 & 0.000 & 0.000 & 0.000 & 0.000 & 0.000 \\
\hline
\end{tabular}




\section{Table 9. The limit super matrix for greenhouse locating}

\begin{tabular}{|c|c|c|c|c|c|c|c|c|c|c|c|c|c|c|c|c|c|c|c|c|c|c|c|c|}
\hline & & \multirow{2}{*}{\begin{tabular}{|l}
$\mathrm{C} 1$ \\
$\mathrm{C} 1-1$ \\
\end{tabular}} & \multicolumn{2}{|c|}{$\mathrm{C} 2$} & \multicolumn{3}{|c|}{$\mathrm{C} 3$} & \multicolumn{3}{|c|}{ C4 } & \multicolumn{2}{|c|}{ C5 } & \multicolumn{4}{|c|}{ C6 } & \multicolumn{3}{|c|}{ C7 } & \multicolumn{5}{|c|}{ A } \\
\hline & & & C2-1 & C2-2 & C3-1 & C3-2 & $3-3$ & C4-1 & C4-2 & $4-3$ & C5-1 & C5-2 & C6-1 & C6-2 & C6-3 & C6-4 & C7-1 & C7-2 & C7-3 & A1 & & A3 & & A5 \\
\hline & C1-1 & 0.146 & .146 & 146 & 146 & 0.146 & 0.146 & 0.146 & 0.146 & 0.146 & 0.146 & 146 & 146 & 0.146 & 146 & 0.146 & .146 & 0.146 & 0.146 & 146 & 0.146 & 0.146 & 0.146 & 146 \\
\hline \multirow[b]{2}{*}{$\mathrm{C} 2$} & & & & & & & & & & & & & & & & & & & & & & & & \\
\hline & C2-2 & 032 & 032 & 032 & .032 & .032 & .032 & 0.032 & 032 & .032 & 0.032 & 032 & 032 & 0.032 & 032 & .032 & 032 & 0.032 & .032 & 032 & 032 & .032 & & 032 \\
\hline \multirow[b]{3}{*}{ C3 } & C3-1 & & & & & & 076 & & & & & & & & & & & & & & & 076 & & .076 \\
\hline & C3-2 & & 015 & 015 & 015 & .015 & .015 & 015 & 015 & 015 & 0.015 & 015 & 015 & 0.015 & 015 & 015 & 015 & & .015 & 015 & & & & .015 \\
\hline & C3-3 & & & & & & & & & & & & & & & & & & & & & & & .016 \\
\hline \multirow[b]{3}{*}{$\mathrm{C} 4$} & & & & .053 & .053 & 0.053 & 0.053 & 0.053 & 0.053 & 0.053 & 0.053 & 053 & 0.053 & 0.053 & 0.053 & 0.053 & .053 & & 0.053 & 053 & & .053 & .053 & 0.053 \\
\hline & C4-2 & & & & & & & & & & & & & & & & & & & & & & & 050 \\
\hline & C4-3 & & & 0.044 & 0.044 & & 0.044 & 0.044 & & & 0.044 & 0.044 & & & & & .044 & & & .044 & & & & $.0+7$ \\
\hline \multirow[b]{2}{*}{ C5 } & C5-1 & & 023 & 023 & .023 & .023 & 0.023 & 0.023 & .023 & 023 & 023 & 023 & & 023 & 0 & 023 & 023 & & .023 & & & 023 & ( & .023 \\
\hline & C5-2 & & & 0.014 & 0.014 & 0.014 & 0.014 & 0.014 & 0.014 & 0.014 & 0.014 & 0.014 & 0.014 & 0.014 & 0.014 & 0.014 & .014 & 0.014 & 0.014 & .014 & & 0.014 & & 0.014 \\
\hline \multirow[b]{4}{*}{ C6 } & C6-1 & & & & & & 58 & 58 & & 58 & & 0.058 & & & & & & & & & & & & 0.058 \\
\hline & C6-2 & & 014 & 0.014 & 0.014 & 0.014 & & & 0.014 & & 0.014 & & 0.014 & 0.014 & 0.014 & 0.014 & .014 & & 0.014 & .014 & & & .014 & 0.014 \\
\hline & C6-3 & & & & & & 23 & 23 & & 023 & & 23 & & 23 & & & 23 & & & 023 & & & & .023 \\
\hline & C6-4 & 0.024 & .024 & 0.024 & 0.024 & 0.024 & 0.024 & 0.024 & 0.024 & 0.024 & 0.024 & 0.024 & & 0.024 & 024 & 0.024 & 024 & & 0.024 & .024 & & & & .024 \\
\hline \multirow[b]{3}{*}{ C7 } & C7-1 & & & & & 0.0 & 0. & 11 & 0.011 & 011 & 0. & 011 & 0. & 0. & & 011 & 011 & 0 & 011 & 011 & 011 & 011 & c & .011 \\
\hline & C7-2 & & & 0.018 & & & & & & & & & & .018 & & & & & & .018 & & & & .010 \\
\hline & C7-3 & 0 . & & & & & 0. & 006 & & & 06 & 006 & & 0 & & 006 & 006 & 006 & 006 & .006. & & 006 & 06 & .006 \\
\hline \multirow[b]{5}{*}{ A } & A 1 & & & 0.091 & 0.091 & & & 0.091 & & 0.091 & & 0.091 & 0.091 & & & & .091 & & 0.091 & .091 & & .091 & & 0.091 \\
\hline & A2 & & & & & & & 0.098 & & & 0.098 & 0.098 & & 0. & & & 098 & 0.098 & .098 & .098 & & .098 & .098 & .098 \\
\hline & A3 & 0.035 & 0.035 & 0.035 & 0.035 & 0.035 & 0.035 & 0.035 & 0.035 & 0.035 & 0.035 & 0.035 & 0.035 & 0.035 & 0.035 & 0.035 & 0.035 & 0.03 & 0.035 & 0.035 & 0.035 & 0.035 & 0.035 & 0.035 \\
\hline & A4 & 0.065 & 0.065 & 0.065 & 0.065 & 0.065 & 0.065 & 0.065 & 0.065 & 0.065 & 0.065 & 0.065 & 0.065 & 0.065 & 0.065 & 0.065 & 0.065 & 0.065 & 0.065 & 0.065 & 0.065 & 0.065 & 0.065 & 0.065 \\
\hline & A5 & 0.052 & 0.052 & 0.052 & 0.052 & 0.052 & 0.052 & 0.052 & 0.052 & 0.052 & 0.052 & 0.052 & 0.052 & 0.052 & 0.052 & 0.052 & 0.052 & 0.052 & 0.052 & 0.052 & 0.052 & 0.052 & 0.052 & 0.05 \\
\hline
\end{tabular}


The alternatives values are shown in their rows in limit super matrix, the alternative that has top value is chosen as the best alternative. To get normal values, raw values are summed up and every row in raw column is divided by the sum. To obtain ideal values, every value in raw values column is divided by the greatest value of the column. The values table, for greenhouse locating model is shown in table 10 .

Table 10: ranking of greenhouse location

\begin{tabular}{|c|c|c|c|c|}
\hline Name & Ideals value & Normal value & Raw value & Ranking \\
\hline$A_{1}$ & 0.925 & 0.267 & 0.091 & 2 \\
\hline$A_{2}$ & 1.000 & 0.288 & 0.098 & 1 \\
\hline$A_{3}$ & 0.354 & 0.102 & 0.035 & 5 \\
\hline$A_{4}$ & 0.662 & 0.191 & 0.065 & 3 \\
\hline$A_{5}$ & 0.527 & 0.152 & 0.052 & 4 \\
\hline
\end{tabular}

Data in table 10 show us that which alternative is the best one. With look over this data we can see Sari region $\left(A_{2}\right)$ is the best city for greenhouses construction in Mazandaran province. The Amol region $\left(\mathrm{A}_{1}\right)$ is the next. The final ranking of the alternatives for greenhouse locating model are given in table 10.

\section{Results and discussions}

Greenhouse construction is an activity with great amounts of money and experts. Supply of food needs is an important problem for people and countries. In this regard, it is a strategic and profitable investment. The most important factor in greenhouse construction investment is the selection of greenhouse location. We use Analytic Network Process to make decision and many factors that influence in such selection are considered. We analysis the clusters affected weights on greenhouse locating in figure 3 .

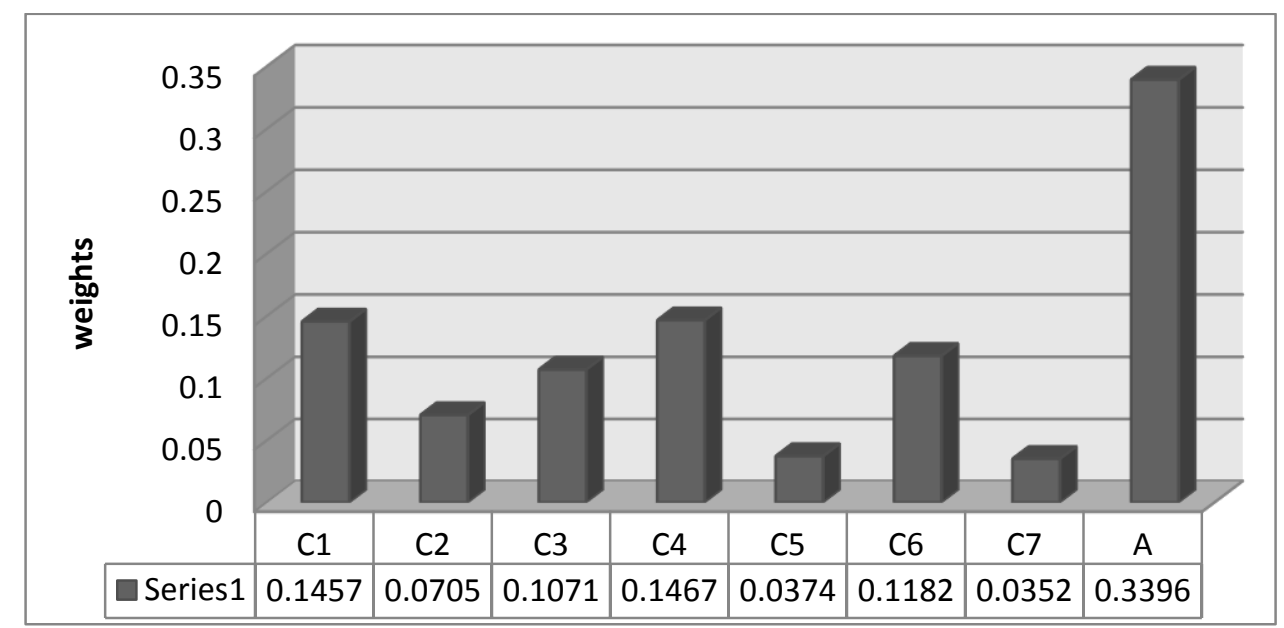

Figure 3. Clusters limit weights in network framework of greenhouse locating model

We look over in figure 3, that locations clusters get the top value; this data shows that selection of the best locations is the most important factors in greenhouse construction.

Many factors influence in greenhouse locating, we have tried to considerate them and form a network structure and allowed all alternatives to take place on the same network, all the factors to be evaluated and results are shown in figure 4. 


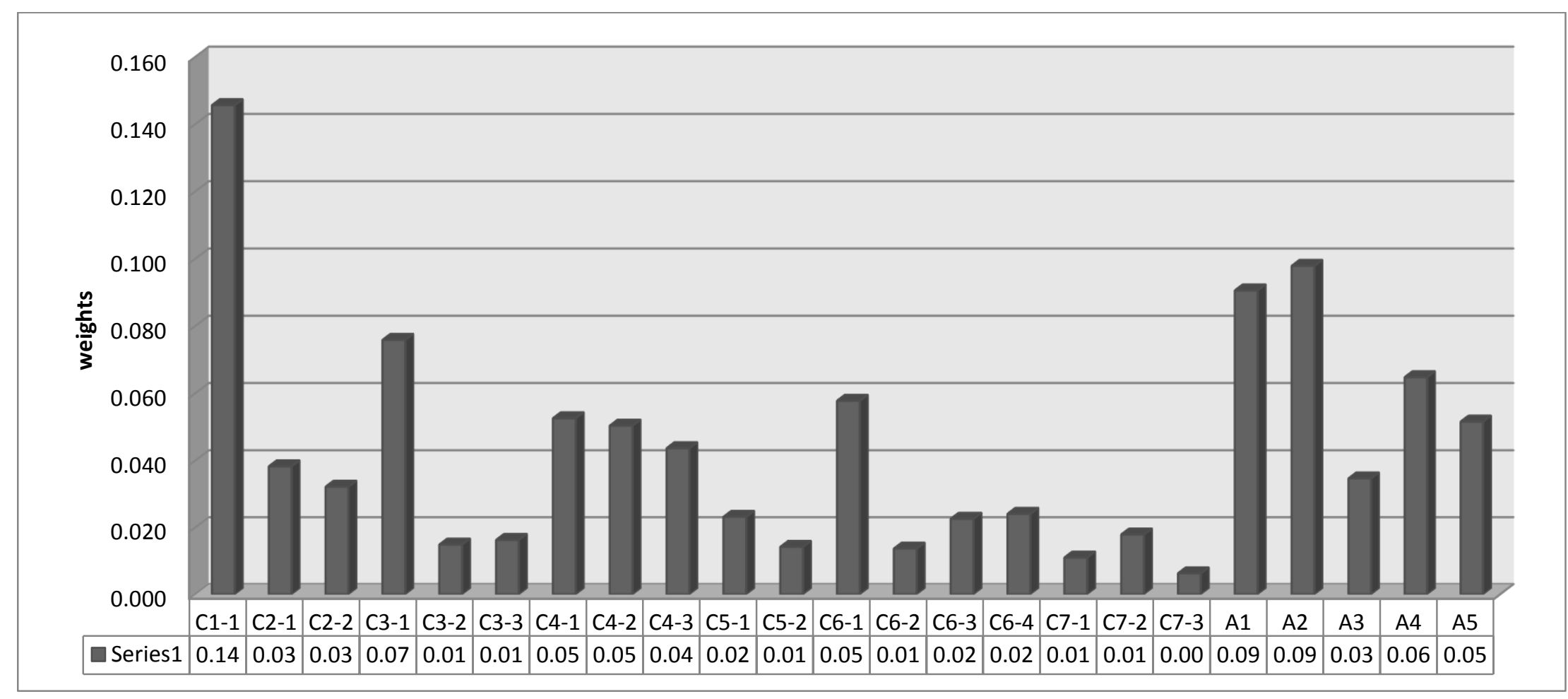

Figure 4. Criteria limit weights in network framework of greenhouse locating model

In fig. 4 , we see that government policy $\left(\mathrm{C}_{1-1}\right)$ has the top influence between all the criteria on greenhouse locating.

In this research, we have tried to select the best greenhouse location. Fuzzy ANP method has been used instead of classical ANP; therefore we eliminate the ambiguity in decision maker's decisions. For this propose Chang $\square \mathrm{s}$ approach is used for gives us the most truthful and suitable greenhouse location. Consequently, for Mazandaran $\square$ s condition, the Sari region is chosen as the most suitable greenhouse location. 


\section{Conclusion}

It is the first duty of investors to transform financial resources into investments in the right places at the right times and earn benefits. However, where to invest and how to invest is always a risky and complicated problem. Greenhouse locating has become one of the most important problems for investors; nevertheless, few applicable models have been addressed that concentrates on this problem. In this research, FANP has been successfully used in selection of appropriate location for greenhouses. The model has many advantages. One of the advantages is that it allows both subjective and objective criteria in decision making process. Moreover, the model is flexible in that new criterion, sub criterion and candidates are easily added to it.

This paper presents a model for greenhouse locating in Mazandaran province that it can be used to improve the performance of greenhouses. In this study, we proposed an effective model for greenhouse locating using FANP method. This application has indicated that the model can be efficiently used in locating and ranking candidates. Proposed model has significantly increased the efficiency of decisionmaking process in greenhouse locating. Although the application of the model proposed in this study

\section{References}

[1] A. F. Guneri, I. M. Cengiz, S. Seker, A fuzzy ANP approach to shipyard location selection, Expert Systems with Applications, 36 (2009) 7992-7999.

[2] S. Jaafarnia, M. Homaei, (2009) Comprehensive and illustrated guide, Greenhouse cultivation of cucumbers and tomatoes,7rd ed., Iran green agriculture school, (2009) 2-10 (in Persian).

[3] M. Hasandokht, Greenhouse management (greenhouse product technologies), 1st ed., Marze danesh publication, (2005) 31-35 (in Persian).

[4] H. Mollahoseini, M. Seylsepur, Greenhouse production management, 1st ed., sarva publication, (2008), (in Persian).

[5] S. Önüt, S. Karar, E. Tugba, A hybrid fuzzy MCDM approach to machine tool selection, Journal of Intelligent Manufacturing, 19 (2008) 443-453.

[6] P. Weber, D. Chapman, Location Intelligence: An Innovative Approach to Business Location Decisionmaking, Transactions in GIS, 15(3) (2011) 309-328.

[7] I. Kaya, Multi criteria Location Selection of Wastewater Treatment Plant by Fuzzy Analytic Hierarchy Process, Journal of Multiple-Valued Logic and Soft Computing 17(4) (2011) 305-320.

[8] S. Önüt, S. Soner, Transshipment site selection using the AHP and TOPSIS approaches under fuzzy environment, Waste Management, 28 (2008) 1552-1559.

[9] M. H. Vahidnia, A. A. Alesheikh, A. Alimohammadi, Hospital site selection using fuzzy AHP and its derivatives, Journal of Environmental Management, 90 (2009) 3048-3056.

[10] M. S. Kuo, Optimal location selection for an international distribution center by using a new hybrid method, Expert Systems with Applications, 38 (2011) 7208-7221.

[11] T. Y. Chou, C. L. Hsu, M. C. Chen, A fuzzy multi-criteria decision model for international tourist hotels location selection, International Journal of Hospitality Management 27 (2008) 293-301.

[12] S. Önüt, T. Efendigil, S. S. Kara, A combined fuzzy MCDM approach for selecting shopping center site: An example from Istanbul, Turkey, Expert Systems with Applications, 37 (2010) 1973-1980.

[13] T. Özcan, N. Çelebi, E. Şakir, Comparative analysis of multi-criteria decision making methodologies and implementation of a warehouse location selection problem, Expert Systems with Applications, 38(8) (2011). 
[14] G. Banias, C. Achillas, C. Vlachokostas, N. Moussiopoulos, S. Tarsenis, Assessing multiple criteria for the optimal location of a construction and demolition waste management facility, Building and Environment, 45(10) (2010) 2317-2326.

[15] W. K. M. Brauers, E. K. Zavadskas, Multi objective optimization in local theory with a simulation for a department store, Transformations in Business \& Economic, 7 (3) (2008) 163-183.

[16] Z. Turskis, E. K. Zavadskas, A new fuzzy additive ratio assessment method (ARAS-F). Case study: the analysis of fuzzy multiple criteria in order to select the logistic centers location, Transport, 25(4) (2010) 423-432.

[17] I. Radfar, S. H. Zolfani, N. Rezaeiniya, M. Shadifar, Using AHP- COPRAS-G method for forest roads locating, in 2nd IEEE International Conference on Emergency "Management and Management Sciences (ICEMMS)", Beijing (2011) 547-550.

[18] E. K. Zavadskas, Z. Turskis, Multiple criteria decision making (MCDM) methods in economics: an overview, Technological and Economic Development of Economy 17(2) (2011) 397-427.

[19] C. L. Hwang, K. Yoon, Multiple Attribute Decision Making: A State of the Art Survey, In: Lecture Notes in Economics and Mathematical Systems 186, Springer-Verlag, Berlin 1981.

[20] C. Zopounidis, M. Doumpos, Multi-criteria Decision Aid in Financial Decision Making: Methodologies and Literature Review, Journal of Multi-Criteria Decision Analysis, 11(2002) 167-186.

[21] J. Figueira, S. Greco, M. Ehrgott, Multiple Criteria Decision Analysis: State of the Art Surveys, Springer, New York 2005.

[22] O. Kaplinski, L. Tupenaite, Review of the Multiple Criteria Decision Making Methods, Intelligent and Biometric Systems Applied in Modern Construction Economics, Transformations in Business \& Economics, 10(1) (2011) 166-181.

[23] O. Kapliński, J. Tamosaitiene, Game theory applications in construction engineering and management, Technological and Economic Development of Economy, 16(2) (2010) 348-363.

[24] J. Tamosaitiene, L. Bartkiene, T. Vilutiene, The New Development Trend of Operational Research in Civil Engineering and Sustainable Development as a result of collaboration between GermanLithuanian-Polish Scientific Triangle, Journal of Business Economics and Management, 11(2) (2010) 316-340.

[25] T. L. Saaty, Decision Making with Dependence and Feedback The Analytic Network Process, RWS Publications, Pittsburgh, 1996.

[26] T. L. Saaty, M. Takizawa, Dependence and independence: From linear hierarchies to nonlinear networks, European Journal of Operational Research, 26 (1686) 229 - 237.

[27] C. Liang, Q. Li, Enterprise information system project selection with regard to BOCR, International Journal of Project Management, 26(8) (2007) 810-820.

[28] S. Boran, K. Goztep, E. Yavuz, A Study On Election Of Personnel Based On Performance Measurement By Using Analytic Network Process (ANP), International Journal of Computer Science and Network Security, 8(4) (2008) 333-338.

[29] M. Dagdeviren, I. Yuksel, M. Kurt, A fuzzy analytic network process (ANP) model to identify faulty behavior risk (FBR) in work system, Safety Science, 46 (2008) 771-783.

[30] Z. Ayag, R. G. Ozdemir, A hybrid approach to concept selection through fuzzy analytic network process, Computers \& Industrial Engineering, 56 (2009) 368-379.

[31] H. R. Yazgan, Selection of dispatching rules with fuzzy ANP approach, The International Journal of Advanced Manufacturing Technology, 170 (2010) 2739-2747.

[32] M. S. Kuo, Optimal location selection for an international distribution center by using a new hybrid method, Expert Systems with Applications, 38 (2011) 7208-7221.

[33] T. L. Saaty, Fundamentals of the Analytic Network Process, ISAHP, Kobe, August, 12-14,(1999) 348379.

[34] T. L. Saaty, Making with Dependence and Feedback, 2nd edition, RWS Publication 2001.

[35] T. L. Saaty, The Analytic Hierarchy Process, McGraw-Hill, New York 1980.

[36] T. L. Saaty, Theory and Applications of the Analytic Network Process: Decision Making with Benefits, Opportunities, Costs, and Risks, RWS Publications, Pittsburg, PA, USA 2005. 
[37] L. A. Zadeh, Fuzzy sets. Information Control, 8 (1965) 338-353.

[38] S. Önüt, S. Soner, Transshipment site selection using the AHP and TOPSIS approaches under fuzzy environment, Waste Management 28 (2008) 1552-1559.

[39] D. Y. Chang, Applications of extent analysis method on fuzzy AHP, European Journal of Operational Research, 95(1996) 649-655. 